\title{
Membrane Estrogen Receptor- $\alpha$ Interactions with Metabotropic Glutamate Receptor 1a Modulate Female Sexual Receptivity in Rats
}

\author{
Phoebe Dewing, ${ }^{1}$ Marissa I. Boulware, ${ }^{2}$ Kevin Sinchak, ${ }^{1}$ Amy Christensen, ${ }^{1}$ Paul G. Mermelstein, ${ }^{2}$ and Paul Micevych ${ }^{1}$ \\ ${ }^{1}$ Department of Neurobiology and Laboratory of Neuroendocrinology of the Brain Research Institute, David Geffen School of Medicine at the University of \\ California, Los Angeles, Los Angeles, California 90095, and 2Department of Neuroscience, University of Minnesota, Minneapolis, Minnesota 55455
}

In rats, female sexual behavior is regulated by a well defined limbic-hypothalamic circuit that integrates sensory and hormonal information. Estradiol activation of this circuit results in $\mu$-opioid receptor (MOR) internalization in the medial preoptic nucleus, an important step for full expression of sexual receptivity. Estradiol acts through both membrane and intracellular receptors to influence neuronal activity and behavior, yet the mechanism(s) and physiological significance of estradiol-mediated membrane responses in vivo have remained elusive. Recent in vitro evidence found that stimulation of membrane-associated estrogen receptor- $\alpha$ (ER $\alpha)$ led to activation of metabotropic glutamate receptor $1 \mathrm{a}$ (mGluR1a). Furthermore, mGluR1a signaling was responsible for the observed downstream effects of estradiol. Here we present data that show that $\mathrm{ER} \alpha$ and mGluRla directly interact to mediate a rapid estradiol-induced activation of MOR in the medial preoptic nucleus, leading to female sexual receptivity. In addition, blockade of mGluRla in the arcuate nucleus of the hypothalamus resulted in a significant attenuation of estradiol-induced MOR internalization, leading to diminished female sexual behavior. These results link membrane-initiated estradiol actions to neural events modulating behavior, demonstrating the physiological importance of ER $\alpha$-to-mGluRla signaling.

Key words: mGluR1a; estradiol; arcuate nucleus; lordosis; $\mu$-opioid receptor internalization; coimmunoprecipitation

\section{Introduction}

In recent years it has become clear that estradiol can signal through membrane-associated estrogen receptors (ERs). These actions are separate from classical estradiol actions mediated by intracellular ERs, which are ligand-activated transcription factors that regulate gene expression and protein synthesis. Nuclear ER effects have a measurable time course of hours to days and play a well established role in estradiol regulation of female rat sexual receptivity. Conversely, membrane ER effects are often observed within seconds to minutes of steroid application, but their physiological significance is less well understood.

Various hypotheses suggest potential mechanisms of membrane-initiated estradiol responses (Filardo et al., 2002; Toran-Allerand et al., 2002; Qiu et al., 2003b), one of which involves estradiol binding to classical ERs at the cell surface plasma membrane (Razandi et al., 2003; Abraham et al., 2004; Chaban et al., 2004). In cultured neurons, estradiol activation of membrane ERs leads to the direct stimulation of metabotropic glutamate

Received Feb. 10, 2007; revised June 8, 2007; accepted July 5, 2007.

This work was supported by National Institutes of Health Grants DA013185 and NS41302.

Correspondence should be addressed to Dr. Paul Micevych, 73-078 CHS, Department of Neurobiology, David Geffen School of Medicine at the University of California, Los Angeles, Los Angeles, CA 90095-1763. E-mail: pmicevych@mednet.ucla.edu.

K. Sinchak's present address: Department of Biological Sciences, California State University, Long Beach, Long Beach, CA 90840-3702.

DOI:10.1523/JNEUROSCI.0592-07.2007

Copyright $\odot 2007$ Society for Neuroscience $\quad$ 0270-6474/07/279294-07\$15.00/0 receptors (mGluRs), independent of glutamate activation (Boulware et al., 2005). This ER/mGluRla interaction provides an explanation for both observed inhibitory and excitatory actions of membrane-initiated estradiol signaling. For example, the decrease of stimulated calcium flux through L-type voltage-gated calcium channels is mediated by mGluR2/3. In contrast, the activation of phospholipase $\mathrm{C}$, inositol trisphosphate receptor, and mitogen-activated protein kinase (MAPK) signaling, resulting in cAMP response element-binding protein (CREB) phosphorylation, is dependent on mGluRla. The present experiments were performed to determine whether mGluR-dependent estradiol signaling, demonstrated in vitro, has a physiological role in modulating female sexual receptivity, a well established behavior that is reliant on estradiol.

The rationale for these studies is based on recent data indicating that estradiol influences sex behavior, not just through intracellular receptors, but also by acting at the membrane surface (Kow and Pfaff, 2004). Little is known, however, about the underlying signaling events mediating these membrane-initiated responses in vivo. Sexual receptivity in female rats is regulated by estradiol acting on a limbic-hypothalamic circuit that integrates sensory, endocrine, and metabolic information (Micevych and Sinchak, 2006). We focused on a portion of this circuit that originates in the arcuate nucleus of the hypothalamus (ARH) and is regulated by estradiol rapidly acting through $\mathrm{ER} \alpha$ (Micevych et al., 2003; Mills et al., 2004). Estradiol control of the lordosis reflex involves the activation and internalization of $\mu$-opioid receptors 
(MORs) in the medial preoptic nucleus (Eckersell et al., 1998; Sinchak and Micevych, 2001). MOR activation/internalization is dependent on estradiol-triggered neuropeptide Y (NPY) release that stimulates NPY-Y1 receptors on $\beta$-endorphin $(\beta$-END) neurons in the ARH (Mills et al., 2004; Sinchak et al., 2006). It is these NPY-receptive ARH neurons that project to the medial preoptic nucleus, release $\beta$-END, and stimulate MOR, leading to their internalization. MOR activation in the medial preoptic nucleus is needed for the complete display of lordosis behavior (Torii et al., 1996; Sinchak et al., 2005), underlining the importance of the projection from ARH to medial preoptic nucleus.

\section{Materials and Methods}

Animals. Male and ovariectomized female (200-250 g) Long-Evans rats were purchased from Charles River (Portage, MI). Females were bilaterally ovariectomized by the supplier. After arrival, male and female rats were housed in a climate-controlled room, two per cage in a $12 \mathrm{~h}$ light/ dark cycle room (lights on at 6:00 A.M.) and provided food and water ad libitum. All experimental procedures were approved by the Chancellor's Animal Research Committee at the University of California, Los Angeles.

Guide cannula implantation surgery. To administer the appropriate drugs to the ARH, female rats were anesthetized with isoflurane $(2-3 \%$ in equal parts oxygen and nitrous oxide) and fixed in a stereotaxic frame. Bilateral guide cannulas (24 gauge; Plastics One, Roanoke, VA) directed at the ARH (coordinates from bregma: anterior, $-2.0 \mathrm{~mm}$; lateral, 0.8 $\mathrm{mm}$; ventral, $-6.9 \mathrm{~mm}$ from dura; tooth bar, $-3.3 \mathrm{~mm}$ ) were implanted using standard stereotaxic procedures. The cannulas were secured to the skull with dental acrylic and stainless steel bone screws. Stylets were placed in the guide cannulas that protruded $<0.5 \mathrm{~mm}$ beyond the opening of the guide cannulas. Animals were singly housed after surgery, received oral antibiotics (trimethoprim and sulfamethoxazole; $0.4 \mathrm{mg} /$ $\mathrm{ml}$; Hi-Tech Pharmacal, Amityville, NY) dissolved in the drinking water, and were allowed to recover $7 \mathrm{~d}$ before behavioral testing.

Steroid priming and behavioral test design. As appropriate, $17 \beta$ estradiol benzoate (EB) was used to either elicit lordosis behavior $(5 \mu \mathrm{g})$ or provide a sub-behavioral $(2 \mu \mathrm{g})$ dose on which the facilitation of the behavior or MOR internalization was studied. EB dissolved in safflower oil was injected subcutaneously in a total volume of $0.1 \mathrm{ml}$. Each female received sequential injections of $\mathrm{EB} 3 \mathrm{~h}$ before the dark phase once per $4 \mathrm{~d}$ cycle. Behavioral testing began $30 \mathrm{~h}$ after EB injection, $3 \mathrm{~h}$ into the dark phase. Female rats were tested for sexual receptivity during the second steroid treatment cycle after surgery to confirm responsiveness to steroids. To study the effect of blocking or activating mGluR1a on lordosis behavior, for the third steroid treatment after cannula implantation, females were first microinjected with a selective mGluRla antagonist, $(S)$ (+)- $\alpha$-amino-4-carboxy-2-methylbenzeneacetic acid (LY367385; Tocris Bioscience, Ellisville, MO), or a selective mGluR1 agonist, $(R S)-3,5-$ dihydroxyphenylglycine (DHPG; Tocris Bioscience), followed by $5 \mu \mathrm{g}$ of EB 30 min later.

To measure sexual receptivity, each female was placed in a Plexiglas testing arena with a stud male, where males were acclimatized to the arenas for at least $30 \mathrm{~min}$ before testing. Males were allowed to vigorously mount females 10 times. The number of times that the female displayed lordosis (lifting of the head, arching of the back, movement of the tail to one side) when mounted by a male was recorded. For each female, a lordosis quotient (LQ) was calculated (number of lordosis displays/number of mounts $\times 100$ ) as a measure of sexual receptivity. Data were analyzed by two-way ANOVA and Student-Newman-Keuls (SNK) post hoc analysis, in which $p<0.05$ was considered significant.

Microinjection. mGluRla antagonist LY367385 (50 nmol) and mGluRla agonist DHPG (50 or $200 \mathrm{nmol}$ ) were dissolved in artificial CSF (aCSF) vehicle. E6-biotin (Steraloids, Newport, RI) and biotin (50 nmol; Sigma-Aldrich, St. Louis, MO) were dissolved in DMSO. Microinjections were done with an infusion pump (Harvard Apparatus, Holliston, MA) at rate of $1.0 \mu \mathrm{l} / \mathrm{min}$. The microinjection needle (28 gauge) protruded $2 \mathrm{~mm}$ beyond the opening of the cannula and was allowed to remain in place for $1 \mathrm{~min}$ after injection to allow for diffusion of drug treatment or aCSF control vehicle from the injector. After microinjec- tion, obturators were reinserted into the guide cannulas, and animals were returned to their home cage until time of behavioral testing.

Confirmation of guide cannula placement. At the end of the behavioral series, animals were anesthetized with sodium pentobarbital ( $100 \mathrm{mg} / \mathrm{kg}$ ) and transcardially perfused with chilled $0.9 \%$ saline, followed with $4 \%$ paraformaldehyde dissolved in $0.2 \mathrm{M}$ Sorenson's phosphate buffer, $\mathrm{pH}$ 7.4. Brains were removed and placed into fixative overnight at $4^{\circ} \mathrm{C}$. The fixative was replaced with $20 \%$ sucrose in phosphate buffer to cryoprotect the tissue. Brains were blocked, sectioned $(20 \mu \mathrm{m})$ on a cryostat (Zeiss, Thornwood, NY), and collected into a chamber filled with PBS. Sections were mounted onto SuperFrost/Plus slides (Fisher, Pittsburgh, PA), stained with thionin, dehydrated, and coverslipped with Permount (Fisher). Injection sites were mapped and verified with bright-field illumination. In nine rats, the cannulas were not positioned in the ARH (located in, above, or lateral to the ventromedial nucleus of the hypothalamus) or the microinfusion compromised the wall of the third ventricle. None of the LY367385-infused animals were misses; all of the misplaced cannulas were in the DHPG experiments. There is no consistent pattern of MOR internalization when cannulas were outside the ARH.

Immunohistochemistry. Animals were perfused as described above 30 min after estradiol injection and immediately processed for immunohistochemistry. For MOR internalization, rabbit primary antibodies directed against MOR (1:24,000; Neuromics, Minneapolis, MN) were used. To look at estradiol activation of intracellular signaling pathways, a rabbit antibody directed against pCREB (1:4000; Millipore, Billerica, MA) was used. Sections that were processed for fluorescence were incubated in blocking buffer (Tyramide Signal Amplification kit; NEN Life Science Products, Boston, MA) and then in biotin-conjugated goat antirabbit IgG (1:200; Vector Laboratories, Burlingame, CA) for $1 \mathrm{~h}$. Tissue was then washed in Tris-buffered saline and incubated in streptavidinhorseradish peroxidase (1:100; NEN Life Science Products) for $30 \mathrm{~min}$, washed, and then incubated for $5 \mathrm{~min}$ in fluorescein-conjugated tyramide or tetramethylrhodamine (Tyramide Signal Amplification kit; 1:50; NEN Life Science Products). Sections were washed again in $0.1 \mathrm{~m}$ Tris buffer and mounted on SuperFrost/Plus slides. Mounted sections were air dried and coverslipped using Vectashield mounting medium (Vector Laboratories).

Colocalization. To determine whether ER $\alpha$ was expressed in cells with mGluR1a, $20 \mu \mathrm{m}$ sections through female ARH were collected and processed as described above. ARH sections were first incubated with a rabbit mGluR1 primary antibody (1:2500; Millipore) overnight at $4^{\circ} \mathrm{C}$ and then processed as previously described with a Fluorescein Tyramide Signal Amplification kit. After incubation with fluorescein tyramide, sections were washed in $0.1 \mathrm{M}$ Tris-buffered saline and incubated with an avidin/biotin-blocking kit (Vector Laboratories) before incubation with a rabbit ER $\alpha$ primary antibody (C1335; 1:10,000; Millipore) for $48 \mathrm{~h}$. Tissue was then washed in $0.1 \mathrm{M}$ Tris-buffered saline before incubation with rhodamine [tetramethylrhodamine isothiocyanate (TRITC)]conjugated AffiniPure goat anti-rabbit IgG (1:200; Jackson ImmunoResearch, West Grove, PA) for $2 \mathrm{~h}$. Sections were washed again in Tris buffer and mounted onto SuperFrost/Plus slides and coverslipped. For quantification of the number of immunofluorescent mGluRla and ER $\alpha$, cells were counted from six sections per animal. Cells were considered colocalization if both mGluR and $\mathrm{ER} \alpha$ immunoreactivity were present.

Image analysis. All immunohistochemically labeled sections were examined with a Zeiss Axioskop 2 equipped with epifluorescent illumination, Axiocam CCD camera, and digital image analysis system to determine colocalization and verify internalization patterns. Fluorescein (FITC) and rhodamine (TRITC) were imaged with a 488 and $550 \mathrm{~nm}$ emission filter and a 515-540 nm and bandpass filter, respectively. Images were adjusted for brightness and contrast using the Zeiss LSM-PC and Adobe (San Jose, CA) Photoshop (version 6.0) programs.

To obtain an estimate of relative internalization, the area of MOR immunoreactivity in the dorsal aspect of the medial preoptic nucleus in every fourth section was estimated using the National Institutes of Health (Bethesda, MD) ImageJ software (version 1.32j). Images taken at a magnification of $360 \times$ were converted to grayscale and adjusted for brightness and contrast in Adobe Photoshop (version 6.0). ImageJ was set to the "pixel inverter" function and calibrated. In each picture, a circle of 
$\sim 60 \mu \mathrm{m}$ diameter was placed on the medial preoptic nucleus and then on another area negative for MOR immunoreactivity. A measurement of the staining was taken in the medial preoptic nucleus and subtracted from the measurement of the background staining, yielding the intensity of MOR immunostaining alone in the medial preoptic nucleus. Studies in our laboratory indicate that internalized MOR immunostaining can be visualized as an increase in MOR immunofluorescence. This has been correlated with our previous method of examining changes in density of MOR-positive processes and has been used to determine the time course and intensity of estradiol-induced activation of MOR in the limbichypothalamic circuit (Sinchak and Micevych, 2003; Mills et al., 2004). Results were compared by two-way ANOVA and SNK post hoc test analysis, in which $p<0.05$ is considered significant. For quantification of pCREB-immunoreactive cells, six sections were counted per animal and compared across the experimental conditions using a $t$ test with differences at the $p<0.05$ level considered significant.

Coimmunoprecipitation. Coimmunoprecipitation was performed using the Catch and Release version 2.0 Reversible Immunoprecipitation System (Millipore). Briefly, immunoprecipitation (IP) samples from lysed HEK-293 cells transfected with mGluRla and either enhanced green fluorescent protein (EGFP)-tagged $\mathrm{ER} \alpha$ or EGFP were incubated with either the polyclonal mGluRla antibody $(4 \mu \mathrm{g}$; BD Biosciences PharMingen, San Diego, CA) or the normal rabbit negative control (4 $\mu \mathrm{g}$; Millipore) in spin columns containing $0.5 \mathrm{ml}$ of IP capture resin for $1 \mathrm{~h}$ at $4^{\circ} \mathrm{C}$ with gentle agitation. Columns were washed three times, followed by sample elution. The eluates were then separated on an SDSpolyacrylamide gel $(4-12 \%)$ and transferred to a nitrocellulose membrane. Membranes were blocked and probed with the monoclonal EGFP antibody $(0.4 \mu \mathrm{g} / \mu \mathrm{l}$; Roche Diagnostics, Indianapolis, IN). An HRPconjugated anti-mouse secondary antibody (1:12,500; Pierce, Rockford, IL) was used for visualization. In additional control experiments, lysate from female hippocampal cultures ( $9 \mathrm{~d}$ in vitro) was used in the immunoprecipitation steps, and $\mathrm{ER} \alpha$ was detected with a polyclonal antibody ( $1 \mu \mathrm{g} / \mu \mathrm{l}$; C1335; Millipore).

Statistical analysis. All data are expressed as the mean \pm SEM. Mean differences between groups were determined using paired $t$ test or oneway or two-way ANOVA followed by SNK post hoc analysis when the main effect or interaction was significant at $p<0.05$. Statistical analysis was conducted using SigmaStat (version 2.03) software. The number of animals used in each experiment is specified in Results for specific experiments.

\section{Results \\ MOR internalization relies on a membrane-localized estrogen receptor}

To test for the involvement of membrane $\operatorname{ER} \alpha$ in regulating the lordosis circuit, E6-biotin, a membrane-impermeable form of estradiol, was injected into the ARH to demonstrate that estradiol acts at the surface of the cell and does not need to penetrate the cell to induce MOR internalization. E6-biotin significantly increased the level of MOR internalization in the medial preoptic nucleus compared with biotin alone (Fig. 1) (one-way ANOVA, $p=0.02 ; \mathrm{df}=19 ; F=9.276 ; \mathrm{SNK}, p<0.05 ; \mathrm{p}=3 ; \mathrm{q}=5.826 ; n=$ 6-7 animals per group). Blocking ERs with ICI182,780 (ICI) prevented estradiol-induced MOR internalization in the medial preoptic nucleus (aCSF plus EB, $96.19 \pm 8.66$; ICI plus EB, $53.84 \pm 4.13$; paired $t$ test, $p=0.008 ; t=3.405 ; \mathrm{df}=9$ ) indicating that estradiol-induced MOR activation is a result of the rapid actions of estradiol at the cell membrane.

\section{mGluR1a and ER $\alpha$ interact in neurons of the ARH}

Colocalization of mGluRla and ER $\alpha$ neurons of the ARH was done immunohistochemically. mGluRla immunoreactivity was localized in $23 \%$ of ER $\alpha$-immunoreactive neurons in the ARH (Fig. 2A-D). Similarly, 22\% of mGluRla-immunoreactive neurons in the ARH were $\mathrm{ER} \alpha$ positive. These results highlight a

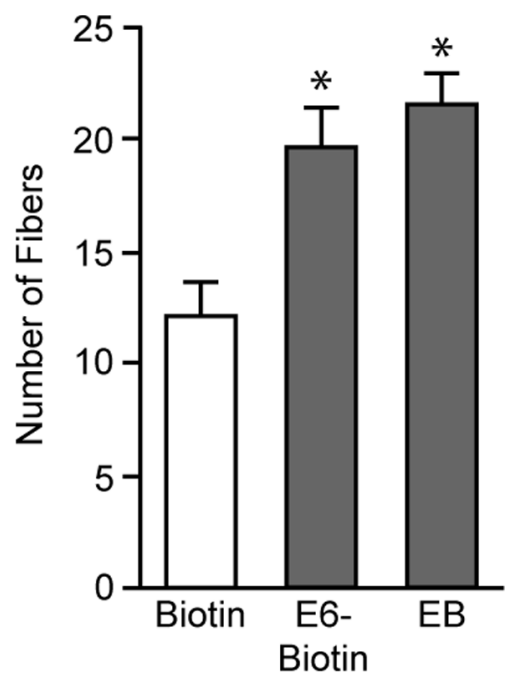

Figure 1. Membrane-impermeable estradiol in the ARH induces MOR internalization. Fiber counting was performed on brain sections from ovariectomized female rats treated with a membrane-impermeable form of estradiol (E6-biotin), biotin alone, and EB (5 $\mu \mathrm{g})$. Both E6biotin and EB caused significant MOR internalization in the medial preoptic nucleus compared with biotin alone, whereas E6-biotin and EB groups exhibit similar numbers of fibers. *Significantly greater than biotin treatment.

population of neurons in the ARH in which $\mathrm{ER} \alpha$ may directly interact with mGluRla.

To test whether ER $\alpha$ can interact with mGluR1a, coimmunoprecipitation experiments were performed. Protein was isolated from HEK-293 cells transfected with mGluRla and either EGFP$\mathrm{ER} \alpha$ or EGFP. EGFP-tagged ER $\alpha$ was used to take advantage of the specificity of EGFP antibodies. As shown in Figure 2E, mGluRla coimmunoprecipitated EGFP-ER $\alpha$. Furthermore, mGluR1a failed to coimmunoprecipitate with EGFP (Fig. $2 F$ ), signifying that coimmunoprecipitation of EGFP-ER $\alpha$ with mGluRla was attributable to mGluRla interacting with ER $\alpha$ and not EGFP. To verify that $\mathrm{ER} \alpha$ could interact with mGluR1a in neurons, we performed additional coimmunoprecipitation experiments using cultured female hippocampal neurons, the preparation in which ER $\alpha$-to-mGluR signaling was initially described. As with the HEK-293 cells, ER $\alpha$ coimmunoprecipitated with mGluR1a (supplemental Fig. 1, available at www.jneurosci.org as supplemental material). Together, these findings strongly suggest a potential physical linkage between $\mathrm{ER} \alpha$ and mGluRla that underlies the ability of membrane-localized ER $\alpha$ to stimulate mGluR1a signaling.

\section{Activation of MOR in the medial preoptic area}

To further understand whether estradiol-induced MOR internalization in the medial preoptic nucleus is dependent on ER $\alpha$ / mGluRla signaling in the ARH, the selective mGluRla antagonist LY367385 was used to pharmacologically block the actions of mGluR1a. Infusion of LY367385 directly into the ARH $30 \mathrm{~min}$ before treating with $\mathrm{EB}(5 \mu \mathrm{g} / 0.1 \mathrm{ml})$ or vehicle $(0.1 \mathrm{ml}$ of safflower oil, s.c.) significantly attenuated EB-induced MOR internalization in the medial preoptic nucleus (Fig. 3A-E) (two-way ANOVA, drug, $p=0.001$; df $=1,17 ; F=14.77$; steroid, $p=$ $0.128 ; \mathrm{df}=1,17 ; F=2.56$; drug $\times$ steroid interaction, $p=0.039$; df $=1,20 ; F=5.01 ;$ SNK, $p<0.001 ; \mathrm{p}=2 ; \mathrm{q}=5.72 ; n=5-8$ animals per group).

To determine whether stimulation of the mGluRla mimicked the estradiol activation of the lordosis-regulating circuit, the selective mGluRla agonist DHPG (200 nmol) was infused into the 

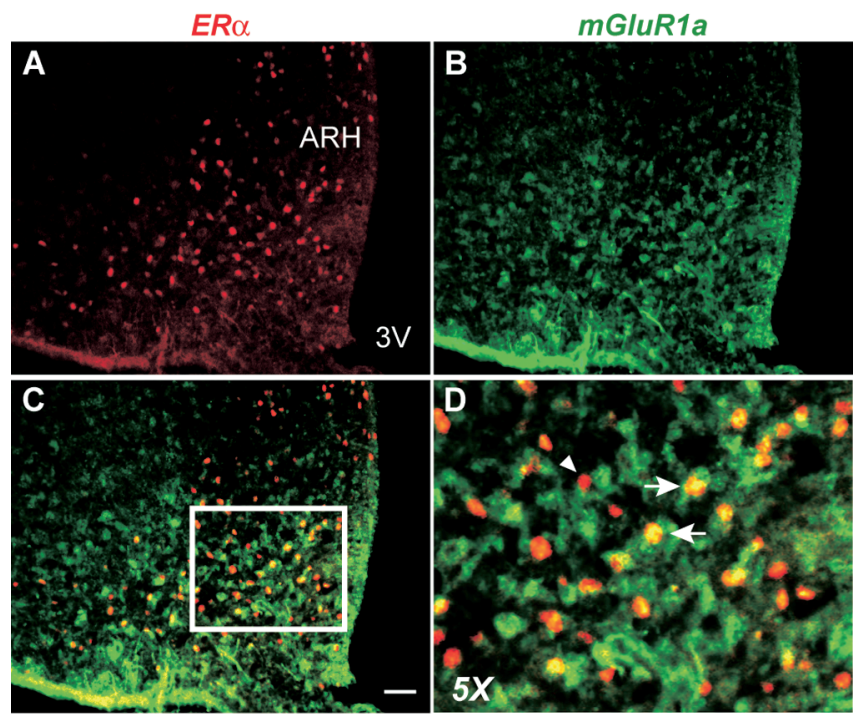

E
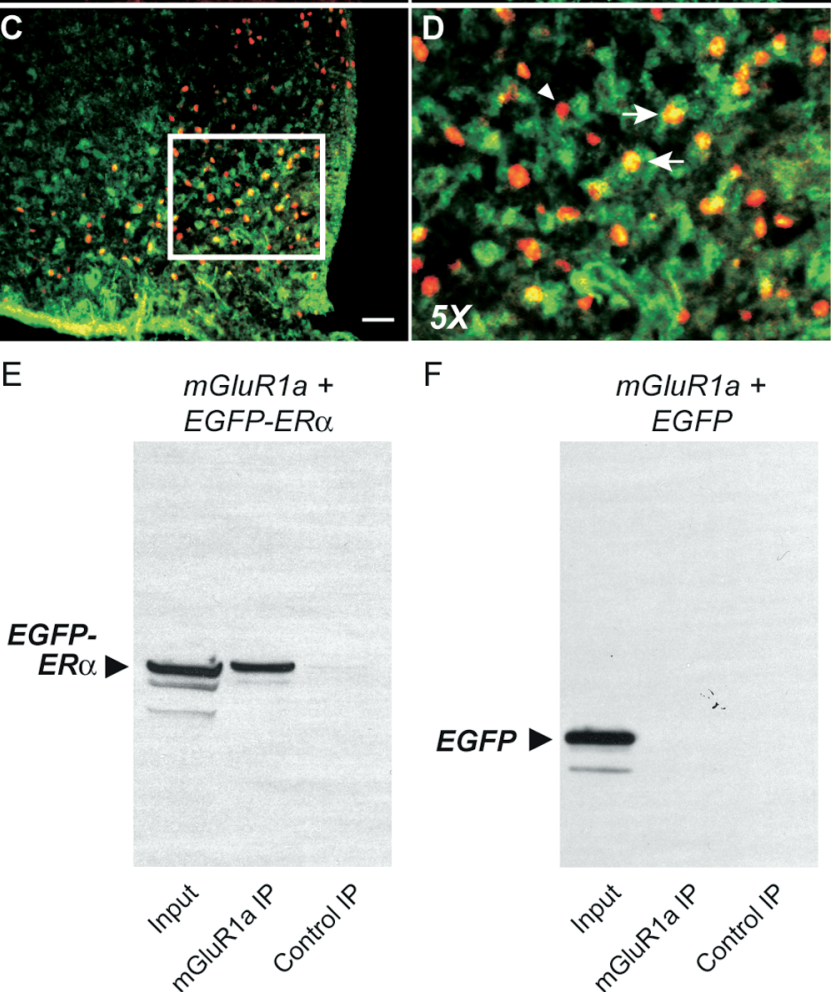

$\mathrm{F}$
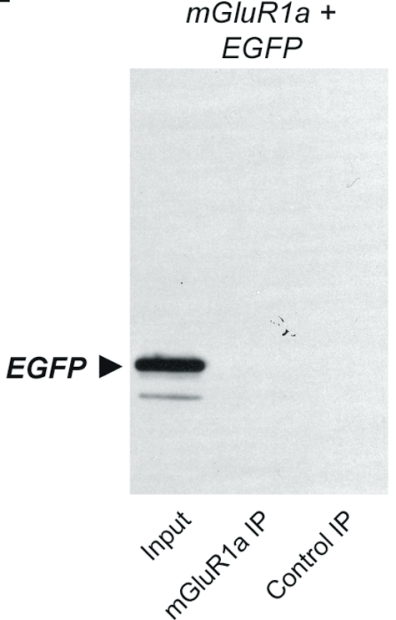

Figure 2. Colocalization and coimmunoprecipitation of $E R \alpha$ and $m G l u R 1 a$. Mediobasal hypothalamic sections from brains of ovariectomized female rats were processed for double-label immunohistochemistry using tyramide signal amplification. $\boldsymbol{A}-\boldsymbol{D}$, Immunohistochemical localization in the ARH of ER $\alpha$ (labeled with TRITC; red; $\boldsymbol{A}$ ), mGluR1a (labeled with FITC; green; $\boldsymbol{B}$ ), and the merged images (indicating colocalization of the immunostained mGluR1a and ER $\alpha$; yellow; $(\boldsymbol{D})$ reveal a colocalization of $\mathrm{mGluR1}$ and $\mathrm{ER} \alpha$. The box in $C$ represents area of higher magnification in $\boldsymbol{D}(5 \times)$. $\boldsymbol{E}, \boldsymbol{F}$, Coimmunoprecipitation of $E R \alpha$ and mGluR1a from protein isolated from HEK-293 cells transfected with mGluR1a and either EGFP-ER $\alpha(\boldsymbol{E})$ or EGFP $(\boldsymbol{F})$. Lysates were immunoprecipitated using either a polyclonal mGluR1a antibody or a contro normal rabbit antibody. The lysate was also run as a positive control (Input). Western blots were then probed with a monoclonal EGFP antibody. mGluR1a coimmunoprecipitated with EGFP$\operatorname{ER} \alpha(\boldsymbol{E})$ but not with $\operatorname{EGFP}(\boldsymbol{F})$, suggesting a direct interaction between mGluR1a and $\mathrm{ER} \alpha$. 3V, Third ventricle. Scale bar, $50 \mu \mathrm{m}$.

ARH 30 min before injections of EB $(2 \mu \mathrm{g} / 0.1 \mathrm{ml})$ or vehicle $(0.1$ $\mathrm{ml}$ of safflower oil, s.c.). Activating mGluRla with DHPG in the absence of EB induced MOR internalization in the medial preoptic nucleus (Fig. $3 F$ ) (two-way ANOVA, drug $\times$ steroid interaction, $p=0.033$; $\mathrm{df}=1,16 ; F=5.69 ; \mathrm{SNK}, p=0.006 ; \mathrm{p}=2 ; \mathrm{q}=$ $4.6 ; n=5-6$ animals per group). This level of internalization was similar to that obtained with estradiol alone or estradiol and DHPG, suggesting that both estradiol and DHPG were acting through the same signaling pathway. To determine whether ICI182,780 acted on mGluR1a, ovariectomized rats were microinjected with ICI182,780 into the ARH 30 min before receiving DHPG. ICI182,780 did not block the DHPG-induced MOR internalization (ICI plus oil, $56.92 \pm 6.6$; ICI plus DHPG, $69.66 \pm$
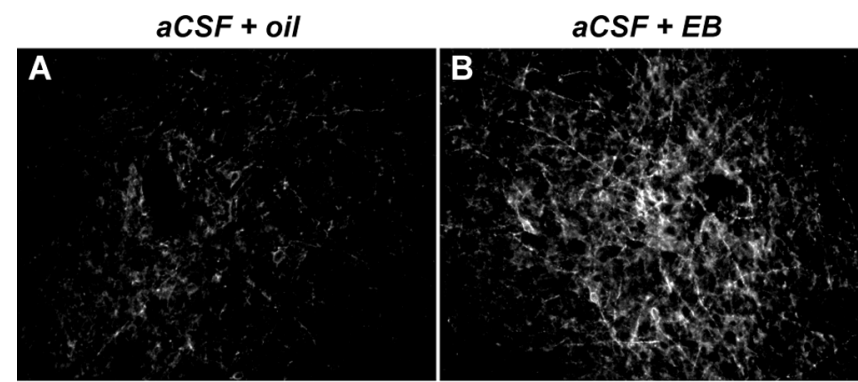

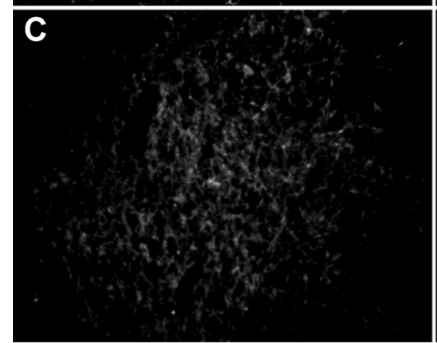

LY367385 + oil

$\mathrm{E}$

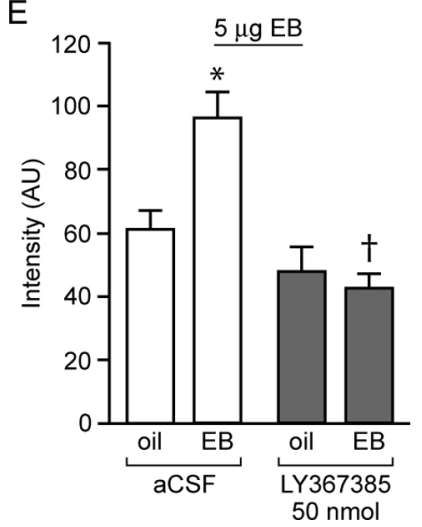

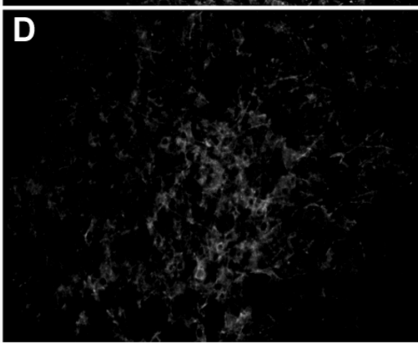

$L Y 367385+E B$

$\mathrm{F}$

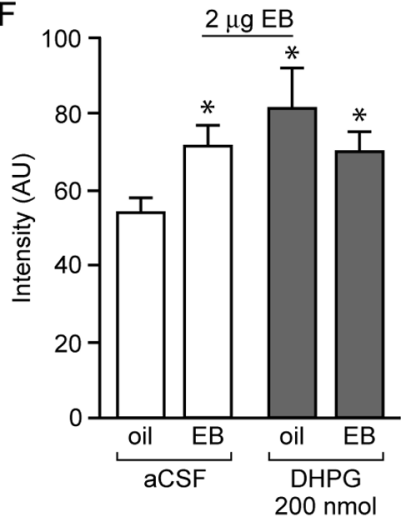

Figure 3. mGluR1a regulation of estradiol-induced MOR internalization in the medial preoptic nucleus (MPN). $\boldsymbol{A}-\boldsymbol{D}$, Images of MOR-immunoreactive fiber density in the MPN of ovariectomized rats that were treated with either $E B$ or oil and received either bilateral microinfusions of aCSF or mGluR1a antagonist LY367385 (50 nmol) into the ARH. $\boldsymbol{A}$, aCSF plus oil group; $\boldsymbol{B}$, LY367385 plus oil; $\boldsymbol{C}$, aCSF plus EB; $\boldsymbol{D}$, LY367385 plus EB. $\boldsymbol{E}$, The histogram illustrates significant mGluR1a antagonist reduction of MOR internalization, as measured by immunofluorescence staining intensity in the MPN of both EB- and oil-treated animals compared with their aCSFtreated controls. $\boldsymbol{F}$, Animals treated with an mGluR1a agonist, DHPG, increased EB-induced MOR internalization. *Significantly greater than oil treatment within aCSF; ${ }^{\dagger}$ significantly different from EB plus aCSF.

0.86; one-way ANOVA on ranks, $H=7.269 ; \mathrm{df}=2 ; p=0.016$; SNK, diff of ranks $=18 ; \mathrm{q}=3.674 ; p<0.05 ; n=4$ animals per group). These data also suggest that activation of ER precedes that of the mGluR1a. Together, these data indicate that mGluR1a is required for estradiol activation of intracellular signaling that mediates MOR internalization/activation in the medial preoptic nucleus.

It was previously shown that estradiol acting through mGluRla triggers mitogen-activated protein kinase-dependent CREB phosphorylation in hippocampal cultures (Boulware et al., 2005). This is a pathway through which membrane actions of estradiol may regulate gene transcription. To determine whether this pathway was being activated, we next evaluated in vivo whether estradiol would increase the numbers of phosphorylated CREB-immunoreactive cells in the ARH. This is a further demonstration of membrane estradiol signaling in the ARH and the importance of ER/mGluRla signaling. Consistent with the 

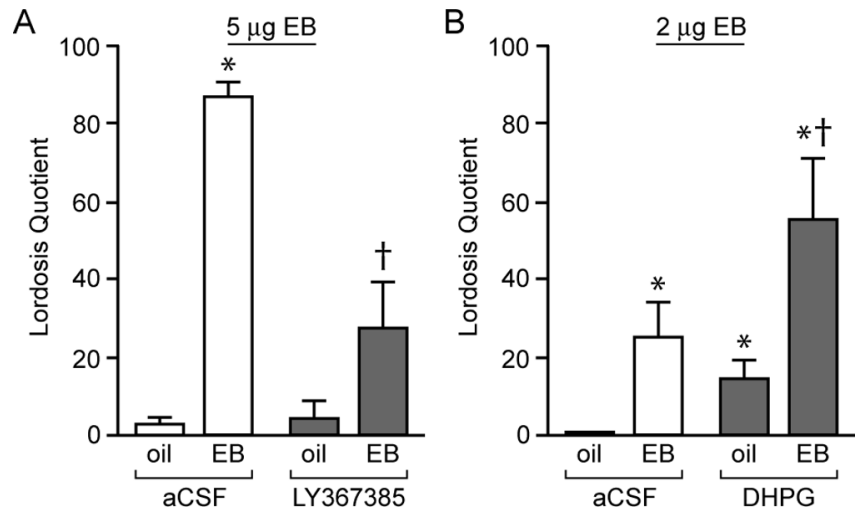

Figure 4. Estrogen receptor and mGluR1a in the ARH modulate sexual receptivity in estradiol-primed female rats. Ovariectomized rats were treated with either $E B(2$ or $5 \mu \mathrm{g})$ or oil 30 min after bilateral infusions into the ARH of either LY367385 (an mGluR1a antagonist), DHPG (an mGluR1a agonist), or aCSF (vehicle). Sexual receptivity was measured by measuring lordosis quotient $30 \mathrm{~h}$ later. $\boldsymbol{A}$, Blocking mGluR1a receptor in the ARH at the time of estradiol treatment in estradiol $(5 \mu \mathrm{g})$-primed ovariectomized female rats revealed a significant decrease in sexual receptivity. $\boldsymbol{B}$, Activating mGluR1a receptors with DHPG in the ARH of EB $(2 \mu \mathrm{g})$-primed ovariectomized female rats revealed a significant increase in sexual receptivity. ${ }^{*}$ Greater than oil treatment within aCSF and EB treatment; ${ }^{\dagger}$ significantly different from EB treatment within drug groups.

hypothesis, after estradiol treatment, the number of phosphoCREB-immunoreactive neurons in the ARH was increased compared with the oil-treated group ( $t$ test, $p=0.02 ; t=$ 3.16 ; $\mathrm{df}=6 ; n=4)$. Additionally, the ability of E6-biotin to increase the numbers of phosphoCREB cells was comparable with that of EB (data not shown).

\section{$\mathrm{ER} \alpha / \mathrm{mGluR} 1 \mathrm{a}$ interactions modulate sexual receptivity}

The rapid activation of the ARH-medial preoptic circuit by estradiol is essential for the full display of sexual receptivity (Torii et al., 1996; Sinchak and Micevych, 2001; Sinchak et al., 2005). To determine whether ER $\alpha$-to-mGluR la signaling was necessary for the lordosis reflex, we antagonized mGluRla in the ARH. LY367385 was microinjected into the ARH $30 \mathrm{~min}$ before EB injection, and the animals were tested $30 \mathrm{~h}$ later to determine their LQ, a quantifiable, estradiol-dependent measure of sexual receptivity. The mGluR1a antagonist LY367385 significantly attenuated the LQ in animals treated with a dose of EB that induces lordosis (Fig. 4A) (two-way ANOVA, drug, $p<0.001$; df = 1,41; $F=75.42$; steroid, $p<0.001 ; \mathrm{df}=1,41 ; F=19.00$; drug $\times$ steroid interaction, $p<0.001 ; \mathrm{df}=1,47 ; F=21.44$; SNK, $p<0.001 ; \mathrm{p}=$ $2 ; \mathrm{q}=9.82 ; n=5-8)$. Furthermore, when the selective mGluR1a agonist DHPG was infused into the ARH, lordosis was facilitated (Fig. $4 B$ ) (two-way ANOVA, drug, $p=0.02 ; \mathrm{df}=1,44 ; F=5.84$; steroid, $p<0.001 ; \mathrm{df}=1,44 ; F=23.48$; drug $\times$ steroid interaction, $p=0.19$; $\mathrm{df}=1,44 ; F=1.76$; SNK, $p=0.005 ; \mathrm{p}=2 ; \mathrm{q}=$ $4.17 ; n=6-12$ per group), as predicted if activation of mGluR 1 a is important for the display of lordosis. As a separate control, when LY367385 was microinjected into the ARH $48 \mathrm{~h}$ after EB in EB- or EB plus progesterone-treated animals, sexual receptivity (measured 30 min later) was neither facilitated nor inhibited, respectively $(2 \mu \mathrm{g}$ of $\mathrm{EB}, \mathrm{LQ}=25.0 \pm 11.9$; $\mathrm{EB}$ plus $\mathrm{P}, \mathrm{LQ}=$ $94.3 \pm 4.0 ; n=5-6$; data not shown). When cannulas were outside the ARH, DHPG did not facilitate lordosis $(n=5)$. These results demonstrate that activation of mGluRla in the ARH is critical during the initial phase of estradiol signaling (Mills et al., 2004). Furthermore, these results also indicate that mGluRla is necessary for estradiol-mediated induction of sexual receptivity but not sexual receptivity itself.

\section{Discussion}

It is well documented that membrane-initiated effects of estradiol exist, but from a mechanistic standpoint, the signaling pathways have remained elusive. The present study demonstrates that specific ER/mGluR1a interactions are of fundamental importance to understanding estradiol signaling in the brain, which in turn mediates behavior. Over the past 20 years, a steady accumulation of data has demonstrated that estrogens can rapidly influence a multitude of intracellular signaling pathways. Examples include estradiol regulation of PKC (Coleman and Smith, 2001), MAPK (Watters et al., 1997; Singh et al., 1999), phospholipase C (Qiu et al., 2003a), phosphatidylinositol 3 kinase (Lee et al., 2005), intracellular calcium (Mermelstein et al., 1996; Chaban et al., 2003), and cAMP/PKA (Aronica et al., 1994; Zhou et al., 1996), all of which have been assumed to be the result of distinct intracellular signaling events. The present study in vivo and previous work in vitro (Boulware et al., 2005) indicate that $\mathrm{ER} \alpha$ can activate the G-protein-coupled mGluRs to initiate intracellular signaling. The differential effects observed by estradiol across cell types may simply reflect the substitution of different classes of mGluRs that interact with membrane ERs.

Membrane-initiated estradiol effects are rapidly initiated but not necessarily short in duration. In fact, once triggered, membrane estradiol effects can be on the order of hours/days, as evidenced by their ability to regulate gene expression and protein synthesis. A clear rapid action of estradiol that appears to be important in such nongenomic to genomic signaling is the phosphorylation of CREB (Wade and Dorsa, 2003; Lee et al., 2004; Boulware et al., 2005). Estradiol has been shown to rapidly increase phosphoCREB in regions associated with the control of reproduction: the medial preoptic area, ventromedial nucleus of the hypothalamus, bed nucleus of the stria terminalis ( $\mathrm{Gu}$ and Moss, 1996; Zhou et al., 1996; Abraham et al., 2004), and the $\mathrm{ARH}$, as determined in the present study. These data provide additional support for ER/mGluR1a interactions mediating intracellular signaling in the ARH, because they recapitulate previous in vitro results (Boulware et al., 2005). Moreover, the increase in pCREB indicates that rapidly initiated membrane actions of estradiol may have long-lasting actions through linkage to regulation of gene expression and protein synthesis. Indeed, rapid membrane-initiated estradiol signaling has been shown to augment estradiol transcriptional regulation (Vasudevan et al., 2005).

It is well known that estradiol regulation of reproduction is dependent on transcriptional regulation, but Kow and Pfaff (2004) have demonstrated that estradiol action at the membrane enhances the effects of intracellular ERs and thus facilitates behavior. It is these important results, demonstrating that both membrane and intracellular ERs are important for estradiol regulation of lordosis behavior, that served as a foundation for the present study. The present results are consistent with the idea that membrane ERs participate in estradiol signaling that induces lordosis. Our studies also extend the previous studies by demonstrating that such rapid actions involve ER signaling through activation of mGluRla receptors.

At the present time, it appears that only $23 \%$ of ERimmunoreactive neurons in the ARH also express mGluR1a. Although this is probably an underestimation because of technical issues of double immunohistochemistry, this is a substantial population. There are, however, many ER-expressing neurons that 
do not have mGluRla. The reason for this has not been elucidated, but a likely possibility is that some ER-expressing neurons do not use membrane-initiated estradiol signaling. In these neurons, estradiol may act through classical intracellular ERs that are ligand-gated transcription factors. Another possibility is that estradiol may be acting through another of the estradiol-binding proteins: G-protein-coupled receptor 30 (GPR30) (Revankar et al., 2005) or ER-X (Toran-Allerand et al., 2002). The present study was based on our previous study that MOR internalization required $\mathrm{ER} \alpha$, because internalization and reproduction was disrupted in $\mathrm{ER} \alpha$ knock-out but not in $\mathrm{ER} \beta$ knock-out animals (Micevych et al., 2003; Abraham et al., 2004; Chaban and Micevych, 2005; Watermann et al., 2006). Moreover, the GPR30 agonist G1 microinjected into the ARH does not internalize MOR in the medial preoptic nucleus (our unpublished results). Together, the results indicate that these particular estradiol actions are mediated through $\mathrm{ER} \alpha$.

The importance of ER $\alpha / \mathrm{mGluR}$ signaling in reproductive behavior can also account for the ability of estradiol to impact diverse intracellular pathways involved in rapid nongenomic signaling that may influence a variety of neural functions. For example, hippocampal neurons in vitro exhibited the full range of $\mathrm{ER} \alpha / \mathrm{mGluR}$ signaling (Boulware and Mermelstein, 2005), and it is in the hippocampus that estradiol influences increases in dendritic length and synaptic inputs with consequences for memory and learning (Woolley, 1998; Foy, 2001; McEwen, 2002). These and the current results support the idea that ER/mGluR signaling is used widely in the brain. Thus, an understanding of ER/mGluR signaling may be relevant not only for estradiol regulation of behavior, but for estradiol-centered therapies for neurological disorders, including neurodegenerative diseases, cognitive dysfunction, pain, epilepsy, and drug abuse (Maiese et al., 2005).

One of the signature actions of estradiol is the regulation of sexual receptivity. The estradiol regulation of this behavior was originally thought to be via intracellular receptors, and certainly this is a large component of estradiol modulation of sexual receptivity. However, the results presented here demonstrate that rapid, membrane $\mathrm{ER} \alpha / \mathrm{mGluR}$ signaling also participates in the regulation of sexual receptivity. We propose that under low systemic estradiol conditions, membrane ERs in the ARH are not activated and result in no MOR internalization/activation in the medial preoptic area. This condition produces a sexually unreceptive female (Fig. 5). However, when systemic estradiol levels reach critical levels, membrane ERs in the ARH are activated, leading to MOR internalization and subsequent full lordosis behavior (Fig. 5). According to our studies, when mGluRla is stimulated with an agonist under low or no estradiol conditions, membrane ERs are bypassed and mGluR1a is directly activated, resulting in MOR internalization and sexual receptivity. Conversely, under high estradiol conditions, antagonizing mGluRla blocks estradiol-induced MOR internalization and attenuates sexual behavior. By demonstrating that this classical assay of estradiol action has a rapid nongenomic component underscores the importance of ER/mGluR interactions in the brain. These data are consistent with the in vitro demonstration of ER $\alpha$ / mGluRla signaling in hippocampal neurons and provide the first evidence in vivo that estradiol can signal through activation of mGluRla. Moreover, these results indicate the necessity for defining genomic and nongenomic components of estradiol regulation of physiology and behavior. Such an analysis will be critical for identifying the exact molecular nature of estradiol signaling underlying the widespread actions of estradiol in the CNS.

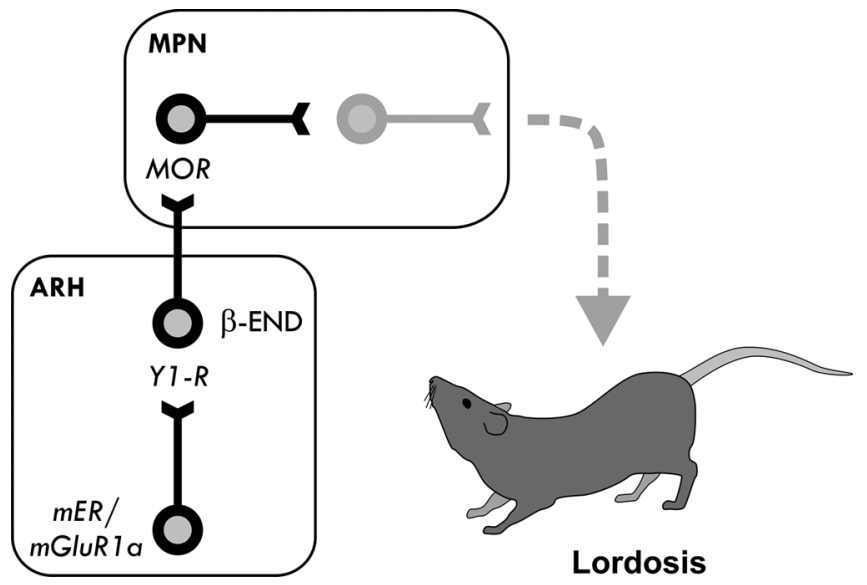

Figure 5. Summary diagram of the ARH-to-medial preoptic nucleus (MPN) projection in the regulation of lordosis. Although it is well known that estradiol acts on intracellular ERs in several locations in the CNS to initiate sexual receptivity, there is increasing evidence that membraneassociated ERs (mER) have a role (Kow and Pfaff, 2004). Part of this lordosis-controlling circuit involves neuropeptide Y-1 receptor (Y1-R)-mediated activation of $\beta$-END neurons that project to the MPN, where they act on the MOR (Mills et al., 2004). Estradiol activates this circuit, inducing rapid internalization/activation of MOR and the eventual facilitation of lordosis (Sinchak et al., 2005). Both estradiol and the membrane-impermeant E6-biotin induced MOR internalization, indicating a role for $m E R$ in this circuit. Blockade of mGluR1a in the ARH prevents MOR internalization and the subsequent estradiol induction of lordosis.

\section{References}

Abraham IM, Todman MG, Korach KS, Herbison AE (2004) Critical in vivo roles for classical estrogen receptors in rapid estrogen actions on intracellular signaling in mouse brain. Endocrinology 145:3055-3061.

Aronica SM, Kraus WL, Katzenellenbogen BS (1994) Estrogen action via the cAMP signaling pathway: stimulation of adenylate cyclase and cAMPregulated gene transcription. Proc Natl Acad Sci USA 91:8517-8521.

Boulware MI, Mermelstein PG (2005) The influence of estradiol on nervous system function. Drug News Perspect 18:631-637.

Boulware MI, Weick JP, Becklund BR, Kuo SP, Groth RD, Mermelstein PG (2005) Estradiol activates group I and II metabotropic glutamate receptor signaling, leading to opposing influences on cAMP response elementbinding protein. J Neurosci 25:5066-5078.

Chaban VV, Micevych PE (2005) Estrogen receptor-alpha mediates estradiol attenuation of ATP-induced $\mathrm{Ca}(2+)$ signaling in mouse dorsal root ganglion neurons. J Neurosci Res 81:31-37.

Chaban VV, Mayer EA, Ennes HS, Micevych PE (2003) Estradiol inhibits atp-induced intracellular calcium concentration increase in dorsal root ganglia neurons. Neuroscience 118:941-948.

Chaban VV, Lakhter AJ, Micevych P (2004) A membrane estrogen receptor mediates intracellular calcium release in astrocytes. Endocrinology 145:3788-3795.

Coleman KM, Smith CL (2001) Intracellular signaling pathways: nongenomic actions of estrogens and ligand-independent activation of estrogen receptors. Front Biosci 6:D1379-D1391.

Eckersell CB, Popper P, Micevych PE (1998) Estrogen-induced alteration of $\mu$-opioid receptor immunoreactivity in the medial preoptic nucleus and medial amygdala. J Neurosci 18:3967-3976.

Filardo EJ, Quinn JA, Frackelton Jr AR, Bland KI (2002) Estrogen action via the G protein-coupled receptor, GPR30: stimulation of adenylyl cyclase and cAMP-mediated attenuation of the epidermal growth factor receptor-to-MAPK signaling axis. Mol Endocrinol 16:70-84.

Foy MR (2001) 17beta-Estradiol: effect on CA1 hippocampal synaptic plasticity. Neurobiol Learn Mem 76:239-252.

Gu Q, Moss RL (1996) 17 $\beta$-Estradiol potentiates kainate-induced currents via activation of the cAMP cascade. J Neurosci 16:3620-3629.

Kow LM, Pfaff DW (2004) The membrane actions of estrogens can potentiate their lordosis behavior-facilitating genomic actions. Proc Natl Acad Sci USA 101:12354-12357.

Lee SJ, Campomanes CR, Sikat PT, Greenfield AT, Allen PB, McEwen BS (2004) Estrogen induces phosphorylation of cyclic AMP response ele- 
ment binding (pCREB) in primary hippocampal cells in a timedependent manner. Neuroscience 124:549-560.

Lee YR, Park J, Yu HN, Kim JS, Youn HJ, Jung SH (2005) Up-regulation of PI3K/Akt signaling by 17beta-estradiol through activation of estrogen receptor-alpha, but not estrogen receptor-beta, and stimulates cell growth in breast cancer cells. Biochem Biophys Res Commun 336:1221-1226.

Maiese K, Chong ZZ, Li F (2005) Driving cellular plasticity and survival through the signal transduction pathways of metabotropic glutamate receptors. Curr Neurovasc Res 2:425-446.

McEwen B (2002) Estrogen actions throughout the brain. Recent Prog Horm Res 57:357-384.

Mermelstein PG, Becker JB, Surmeier DJ (1996) Estradiol reduces calcium currents in rat neostriatal neurons via a membrane receptor. J Neurosci 16:595-604.

Micevych PE, Sinchak K (2006) The neurochemistry of limbichypothalamic circuits regulating sexual receptivity. In: Handbook of neurochemistry and molecular neurobiology, Ed 3 (Blaustein J, ed). New York: Springer.

Micevych PE, Rissman EF, Gustafsson JA, Sinchak K (2003) Estrogen receptor-alpha is required for estrogen-induced mu-opioid receptor internalization. J Neurosci Res 71:802-810.

Mills RH, Sohn RK, Micevych PE (2004) Estrogen-induced $\mu$-opioid receptor internalization in the medial preoptic nucleus is mediated via neuropeptide Y-Y1 receptor activation in the arcuate nucleus of female rats. J Neurosci 24:947-955.

Qiu J, Wang CG, Huang XY, Chen YZ (2003a) Nongenomic mechanism of glucocorticoid inhibition of bradykinin-induced calcium influx in PC12 cells: possible involvement of protein kinase C. Life Sci 72:2533-2542.

Qiu J, Bosch MA, Tobias SC, Grandy DK, Scanlan TS, Ronnekleiv OK, Kelly MJ (2003b) Rapid signaling of estrogen in hypothalamic neurons involves a novel G-protein-coupled estrogen receptor that activates protein kinase C. J Neurosci 23:9529-9540.

Razandi M, Alton G, Pedram A, Ghonshani S, Webb P, Levin ER (2003) Identification of a structural determinant necessary for the localization and function of estrogen receptor alpha at the plasma membrane. Mol Cell Biol 23:1633-1646.

Revankar CM, Cimino DF, Sklar LA, Arterburn JB, Prossnitz ER (2005) A transmembrane intracellular estrogen receptor mediates rapid cell signaling. Science 307:1625-1630.

Sinchak K, Micevych PE (2001) Progesterone blockade of estrogen activation of $\mu$-opioid receptors regulates reproductive behavior. J Neurosci 21:5723-5729.
Sinchak K, Micevych P (2003) Visualizing activation of opioid circuits by internalization of $\mathrm{G}$ protein-coupled receptors. Mol Neurobiol 27:197-222.

Sinchak K, Shahedi K, Dewing P, Micevych P (2005) Sexual receptivity is reduced in the female mu-opioid receptor knockout mouse. NeuroReport 16:1697-1700.

Sinchak K, Romeo HE, Micevych PE (2006) Site-specific estrogen and progestin regulation of orphanin $\mathrm{FQ} /$ nociceptin and nociceptin opioid receptor mRNA expression in the female rat limbic hypothalamic system. J Comp Neurol 496:252-268.

Singh M, Setalo Jr G, Guan X, Warren M, Toran-Allerand CD (1999) Estrogen-induced activation of mitogen-activated protein kinase in cerebral cortical explants: convergence of estrogen and neurotrophin signaling pathways. J Neurosci 19:1179-1188.

Toran-Allerand CD, Guan X, MacLusky NJ, Horvath TL, Diano S, Singh M, Connolly Jr ES, Nethrapalli IS, Tinnikov AA (2002) ER-X: a novel, plasma membrane-associated, putative estrogen receptor that is regulated during development and after ischemic brain injury. J Neurosci 22:8391-8401.

Torii M, Kubo K, Sasaki T (1996) Influence of opioid peptides on the priming action of estrogen on lordosis in ovariectomized rats. Neurosci Lett 212:68-70.

Vasudevan N, Kow LM, Pfaff D (2005) Integration of steroid hormone initiated membrane action to genomic function in the brain. Steroids 70:388-396.

Wade CB, Dorsa DM (2003) Estrogen activation of cyclic adenosine 5' monophosphate response element-mediated transcription requires the extracellularly regulated kinase/mitogen-activated protein kinase pathway. Endocrinology 144:832-838.

Watermann DO, Tang Y, Zur Hausen A, Jager M, Stamm S, Stickeler E (2006) Splicing factor Tra2-beta1 is specifically induced in breast cancer and regulates alternative splicing of the CD44 gene. Cancer Res 66:4774-4780.

Watters JJ, Campbell JS, Cunningham MJ, Krebs EG, Dorsa DM (1997) Rapid membrane effects of steroids in neuroblastoma cells: effects of estrogen on mitogen activated protein kinase signalling cascade and c-fos immediate early gene transcription. Endocrinology 138:4030-4033.

Woolley CS (1998) Estrogen-mediated structural and functional synaptic plasticity in the female rat hippocampus. Horm Behav 34:140-148.

Zhou Y, Watters JJ, Dorsa DM (1996) Estrogen rapidly induces the phosphorylation of the cAMP response element-binding protein in rat brain. Endocrinology 137:2163-2166. 